\begin{tabular}{ll} 
Abstract G181(P) Table 3 Most common themes & \\
\hline & $\begin{array}{l}\text { Number of } \\
\text { respondents }\end{array}$ \\
\hline Theme of learning & 20 \\
\hline Useful approaches when discussing safeguarding concerns with parents & 16 \\
Referral and legal processes in safeguarding & 11 \\
Consideration of family risk factors & 9 \\
Understanding of multi-disciplinary working & 7 \\
Improved knowledge of symptoms and signs of child abuse & \\
\hline
\end{tabular}

parents about safeguarding concerns and understanding referral and legal processes.

\section{G182(P) SURVEY TO INVESTIGATE NEONATAL KNOWLEDGE AND EXPERIENCE AMONGST NEWLY QUALIFIED GENERAL PRACTITIONERS}

S Omar, M Dhami, A Skinner. Neonatal Department, New Cross Hospital, Wolverhampton, UK

\subsection{6/archdischild-2015-308599.176}

Aim To investigate level of neonatal knowledge and experience amongst newly qualified General Practitioners (GPs) who completed the vocational training scheme (VTS).

Method An online survey distributed via email to GPs who qualified from two GP Deaneries since 2009. The survey consisted of 24 questions, mainly multiple choice and self-rating scales, and was completed between May and June 2014.

Results There were 38 respondents. Of these, 58\% had completed a paediatric placement during their VTS. Placement length varied from 3 months (1 responder), 4 months (11 responders) to 6 months (10 responders). Forty-five percent (17/ 38) gained neonatal experience, comprising of neonatal life support courses, neonatal ward rounds, attending high risk deliveries and completing baby checks.

Eighty percent of responders were less than 2 years post VTS qualification, with a median age of 31-35 years. Despite completing their VTS and 60\% receiving formal teaching on newborn examination, $25 \%$ of responders did not feel confident in completing a 6-8 week newborn examination. In 50\% of practices where our study population are currently based a dedicated health professional undertakes the baby checks.

The GPs portrayed good knowledge of common neonatal problems such as gastro-oesphageal reflux disease, and on selfrating, the majority were confident of their ability to diagnose mongolian blue spots, port wine stain and a significant heart murmur. However, over 35\% displayed definite uncertainty in diagnosing naevus flammeus and erythema toxicum. Only $12 \%$ felt confident in recognising cow's milk protein intolerance and $56 \%$ were unaware of when to diagnose prolonged jaundice.

The main information source used by the newly qualified GPs was GP notebook, with $72 \%$ identifying this source and less than $30 \%$ consulting formal guidelines.

Conclusion A significant number of GPs qualify from the VTS without completing a paediatric placement and even fewer are gaining neonatal experience. Post-qualification, there continues to be limited exposure to infants as dedicated health professionals complete their routine care. It is essential to recognise this lack of exposure and make appropriate changes to GP training to provide basic, structured neonatal experience, thereby ensuring confidence in neonatal assessment and management amongst front-line medical practitioners.

\section{G183(P) LEARNING TOGETHER STUDY DAYS: CROSS SPECIALTY EDUCATION TO IMPROVE CHILDREN AND YOUNG PEOPLE'S HEALTH}

${ }^{1} \mathrm{DR}$ James, ${ }^{2} \mathrm{H}$ Race, ${ }^{3} \mathrm{C}$ Sen, ${ }^{4} \mathrm{~K}$ Fawbert. ${ }^{1}$ Paediatric and Adolescent Medicine, University College Hospital, London, UK; ${ }^{2}$ Paediatrics, West Middlesex Hospital, London, UK; ${ }^{3}$ Paediatric Nephrology, Great Ormond Street Hospital, London, UK; ${ }^{4}$ London School of Paediatrics, Health Education North West London, London, UK

\subsection{6/archdischild-2015-308599.177}

Aims The UK is lagging behind the majority of Europe in children and young people's health outcomes. ${ }^{1}$ One possible hypothesis for this is the lack of integration between primary, secondary and tertiary care. The World Health Organisation supports effective inter-professional education as it enables effective and collaborative practice. $^{2}$ There is published evidence that inter-professional learning can lead to better patient care and safety, reduced mortality rates and better use of specialist health resources. $^{3-5}$

Methods Following focus group work and a pilot study day, the authors created three study days: Child and Adolescent Mental Health, Public Health and Adolescent Sexual Health. These are areas where good care crosses traditional medical specialties and health care professions. Royal College curricula were analysed to define learning outcomes. The study days were advertised to paediatric, GP and relevent specialty trainees as well as other children's and young people's health professionals. Each day featured a mix of lecture and small group case based learning.

Results The three days were attended by 163 trainees ( 85 paediatric, 52 GP, 26 other). We received pre and post course online feedback from $85(53 \%)$ and 104 (64\%) trainees respectively. Across the three days the proportion of delegates who strongly agreed with the statement 'My learning is enhanced when I learn with health care professionals from different specialties' increased from 40.7 to $60.2 \%$ (Tables 1 and 2).

Abstract G183(P) Table 1 Proportion self-assessing their confidence as very confident/confident

\begin{tabular}{lll}
\hline & Pre course & Post course \\
\hline Sexual Health & $44 \%$ & $91 \%$ \\
Mental Health & $18 \%$ & $80 \%$ \\
Public Health & $32 \%$ & $77 \%$ \\
\hline
\end{tabular}

Abstract G183(P) Table 2 Proportion self-assessing their knowledge as very good/good

\begin{tabular}{lll}
\hline & Pre course & Post course \\
\hline Sexual Health & $44 \%$ & $91 \%$ \\
Mental Health & $35 \%$ & $77 \%$ \\
Public Health & $32 \%$ & $80 \%$ \\
\hline
\end{tabular}

Conclusions This series demonstrates that it is both desirable and feasible to offer cross specialty inter-professional education in Children and Young People's health and that it not only increases confidence and knowledge in the individual subject areas but also improves the delegates' own perceptions of learning in the wider cross specialty team.

\section{REFERENCES}

1 Wolfe I, Thompson M, Gill P, et al. Health services for children in Western Europe. Lancet 2013;381(9873):1224-1234 
2 WHO Framework for Action on Interprofessional Education $\{\$\}$ Collaborative Practice 2010

3 Simmonds $\mathrm{S}$, Coid J, Joseph $\mathrm{P}$, et al. Community mental health team management in severe mental illness: a systematic review. $\mathrm{Br} /$ Psychiatry 2001;178:497-502

4 Naylor CJ, Griffiths RD, Fernandez RS. Does a multidisciplinary total parenteral nutrition team improve outcomes? A systematic review. I Parenter Enteral Nutr. 2004; $28: 251-258$

5 Holland R, Battersby J, Harvey I, et al. Systematic review of multidisciplinary interventions in heart failure. Heart 2005;91:899-906

\section{G184(P) THE "CASE EXCHANGE" - INTEGRATING PATIENTS AS EDUCATORS AS PART OF A NEW REGIONAL PAEDIATRIC TEACHING PROGRAMME}

A Sepahzad, A Anpananthar, S Alexander, B Klaber. Paediatrics, London School of Paediatrics, London, UK

\subsection{6/archdischild-2015-308599.178}

Aims We developed a regional teaching programme for Paediatric trainees, with the main aims of integrating patients as educators, providing $\mathrm{RCPCH}$ curriculum-matched teaching through case-based learning and promoting the sharing of good practice.

Methods The region boasts a wealth of expertise in both general and specialist Paediatric care. The training programme relies on the acquisition of knowledge and experience as trainees rotate through various posts in the region.

Verbal feedback highlighted difficulties for the trainee, in gaining exposure to all specialist areas and the absence of regional curriculum-matched teaching for Level 1 trainees. There is a growing focus on the patient experience in undergraduate curricula, but we observed less focus in postgraduate education.

We developed a monthly regional teaching programme, which launched in 2014. These were 2-hour evening sessions held at a central location. Sessions included the unique feature of a patient/parent talk, $\mathrm{SHO}$ and $\mathrm{SpR}$ delivered case presentations and keynote Consultant talks. To ensure sustainability and exposure to all sub-specialist services, each "C-EX" was organised by a different Trust, with the aid of an electronic session planning "C-EX package".

Results A series of seven sessions were carried out with all Trusts enthusiastically hosting a "Case Exchange" session. There were approximately 25 attendees per session ranging from medical student to consultant level.

Feedback questionnaire data was sampled from one session. A semantic differential scale was used to evaluate usefulness and presentation quality ( $1=$ very poor, $5=$ excellent). 23 of 27 attendees completed a questionnaire. For usefulness, the percentage of responders scoring "excellent" for the patient/parent talk, consultant talk and trainee case presentations were 95\%, 90\% and $78 \%$ respectively. For presentation quality, this was $86 \%$, $83 \%$ and $48 \%$ respectively. Attendees commented: "it was "refreshing to hear the patient experience" and that "the patient session has changed my future practice". Demonstrating its success, the "Case Exchange" is being implemented in other regions.

Conclusion The "Case Exchange" highlights the value of involving patients/parents in learning events, thus we recommend its formal integration into postgraduate teaching. Offering patients a platform to share their views, we empower them to shape our training and reinforce the mantra of patient-centred care.

\section{G185(P) INNOVATIVE E-LEARNING: A UK INITIATIVE TO ADVANCE UNDERGRADUATE PAEDIATRIC MEDICAL EDUCATION}

'S Vernon, 'S Russell, 'A Nesbitt, ${ }^{2} \mathrm{~B}$ Morrissey. 'Department of Medicine, University College London, London, UK; ${ }^{2}$ Whittington Hospital, London, UK

\subsection{6/archdischild-2015-308599.179}

Aim In the USA, on-line interactive clinical cases are increasingly being used to support and deliver the undergraduate paediatric curriculum. The use of e-learning in undergraduate paediatrics in the UK is limited by a lack of case complexity and instantaneous feedback to learners. We aimed to develop and evaluate an interactive and accessible paediatric case scenario for undergraduates.

Methods Clinical students at a UK medical school were surveyed using a Google Docs questionnaire. Their feedback was used to develop an innovative powerpoint-based e-learning format. Our two simulated cases, on neonatal jaundice and neonatal sepsis, aimed to replicate real-life clinical practice. By presenting learners with several different clinical scenarios simultaneously we hoped to further their competency in clinical decision making, patient prioritisation, prescribing skills and emergency care. Hyperlinks were utilised to allow for instantaneous feedback, enable easy access to external resources (e.g. NICE) and simulate consequences for learners' decisions. Upon completion students were asked to fill out a second feedback survey. Numerical data was analysed in Stata 12.1 using the Wilcoxon signed rank test, and free-text responses evaluated thematically.

Results 59 students responded to the initial survey. 85\% stated that they used case studies primarily to consolidate knowledge and effectively test understanding. 83\% wanted instant and easy access to more case studies. Learners expressed frustration that current online cases focussed on barn door presentations that did not identify gaps in their knowledge. There was concern that current cases were unrealistic and lacked integration of problem solving skills. Learners were also dissatisfied at the time lag between answering white space questions and receiving feedback.

Students' self-rated knowledge increased from 2.51/4 (95\% $\mathrm{Cl} 2.27-2.76)$ to $3.6 / 4$ (95\% Cl 3.41-3.79), after completing the case study; $p<0.0001$. Students valued having to 'prioritise multiple patients' and 'make decisions about the child's care'. They praised 'the ability to interact with the powerpoint', and the provision of concise, relevant and instantaneous feedback.

Conclusion We have designed a novel, effective and inexpensive case study format that supports learning in paediatrics. Our e-learning method mirrors the complexities and challenges of real-life clinical practice and enables development of clinical decision making.

\section{G186(P) MULTI-SOURCE FEEDBACK - DOES IT REALLY ENCOURAGE CHANGE? A QUALITATIVE STUDY EXPLORING PAEDIATRIC TRAINEES' PERCEPTIONS OF MULTISOURCE FEEDBACK}

${ }^{1} \mathrm{NL}$ Amin, ${ }^{2} \mathrm{~S}$ Uka. ${ }^{1}$ Paediatric Medicine, Leeds Children's Hospital, Leeds, UK; ${ }^{2}$ Paediatric Medicine, Calderdale Royal Hospital, Halifax, UK

\subsection{6/archdischild-2015-308599.180}

Aims This project aimed to look at how multi-source feedback (MSF) is currently being used within Paediatric medicine. We hoped to explore the trainees' perception of current feedback, and discuss how to maximise the formative potential of MSF for future years. 